\title{
Neonatal Mortality and Morbidity in a Tertiary Care Hospital of Coastal South India
}

Kannan $\mathrm{R}^{1}$, Rao $\mathrm{S}^{2}$, Mithra $\mathrm{P}^{3}$, Rajesh $\mathrm{SM}^{4}$, Unnikrishnan $\mathrm{B}^{5}$, Rekha $\mathrm{T}^{6}$

\begin{abstract}
Introduction: Progress in new-born survival has been slow. There is a variation in neonatal death rates across states and geographical region of a country. Understanding the pattern of mortality is essential in improving new-born survival. This study was conducted to study the mortality and morbidity profile in Neonatal Intensive Care Unit (NICU) of a university teaching hospital. Material and Methods: This was a retrospective descriptive study including records of all neonates admitted in NICU from January 2015 to December 2016. Results 3623 neonates were admitted during the study period. Majority were preterm and low birth weight babies. Neonatal jaundice $(41.4 \%)$ was the leading cause of admission. Major cause of morbidity was sepsis (26.2\%). Average duration of stay were higher in out borns (8.4 days) compared to inborn (6.5 days) neonates. Among mortality a higher male predominance was seen. Neonatal sepsis (36.3\%) was the single most common cause of mortality followed by respiratory distress syndrome (27.4\%) and congenital malformations (18.6\%). Out born neonates which were self-transported had higher mortality rate than transported by ambulance. Conclusion This study identifies sepsis, prematurity and low birth weight as the major causes of morbidity. Sepsis, respiratory distress syndrome and congenital malformations were the leading causes of mortality Understanding causes of neonatal mortality may help to implement interventions to promote new-born survival.
\end{abstract}

Key words: Mortality, Morbidity, New-born, Sepsis

\section{Introduction}

$\mathrm{N}$ eonatal period is the most unguarded period which influences the survival and overall wellbeing of a child ${ }^{1}$. Many illnesses affecting the neonates lead to morbidities and mortality among them. According to 2015 Global Health Observatory (GHO) data, neonatal deaths constitute roughly $45 \%$ of all under five deaths ${ }^{2}$. Worldwide, Neonatal mortality rate has seen a steady decline by $47 \%$ between 1990 and 2015 from 36 to 19 per 1000 live birth². Total number of neonatal deaths fell from 5.1 million to 2.7 million during the same period ${ }^{3}$.Of the 2.7 million deaths, 1 million deaths happen on the first day and approximately 2 million deaths in the first week of life $\mathrm{f}^{2,10}$. Overall, there is decline in under-5 mortality at global level, however neonatal mortality
${ }^{1}$ Dr. Raja Kannan, MBBS. MD, Senior Resident, Department of Paediatrics, ${ }^{2} \mathrm{Dr}$. Suchetha Rao, MBBS. MD. Associate Professor, Department of Paediatrics, ${ }^{3}$ Dr. Prasanna Mithra, MBBS, MD, Associate Professor, Department of Community Medicine, ${ }^{4}$ Dr. Rajesh SM (Major), MBBS. MD, Associate Professor, Department of Paediatrics, ${ }^{5} \mathrm{Dr}$. Bhaskaran Unnikrishnan, MBBS. MD, Professor, Department of Community Medicine, ${ }^{6} \mathrm{Dr}$. Rekha T, MBBS. MD, Associate Professor, Department of Community Medicine. All from the Kasturba Medical College (Manipal Academy of Higher Education), Mangalore, India.

\section{Address for correspondence \\ Dr. Suchetha Rao \\ Associate Professor \\ Department of Paediatrics \\ Kasturba Medical College Mangalore \\ Manipal Academy of Higher Education (MAHE), \\ Manipal, India \\ Tel No.: +919901765707 \\ E-mail: suchetha.rao@manipal.edu}

\section{Acknowledgements: None \\ Funding: Nil \\ Conflict of Interest: None \\ Permission from IRB: Yes}

\section{How to cite}

Kannan R, Rao S, Mithra P, Rajesh SM, Unnikrishnan B, Rekha T. Neonatal Mortality and Morbidity in a Tertiary Care Hospital of Coastal South India. J Nepal Paediatr Soc 2017;37(3):232-237.

doi:http://dx.doi.org/10.3126/jnps.v37i3.18734

This work is licensed under a Creative Commons Attribution 3.0 License. 
still remains high and is a major contributor to under-5 mortality ${ }^{2}$. Currently several Asian countries, including India are in this phase, despite the developments in maternal and child health care services ${ }^{4}$.

India contributes to nearly $25 \%$ of the mortality around the world ${ }^{3,5,8}$. According to the National Family Health Survey (NFHS) III report, Neonatal Mortality Rate (NMR) in India was 39 per 1,000 live births, being responsible for nearly $77 \%$ of all the infant deaths and nearly half of the under-five child deaths ${ }^{6,7,9}$. Also, there is a variation of neonatal death rates across states and geographical regions within India ${ }^{3,6,7,11}$. The challenge ahead of us is to meet every newborn target of ten or fewer neonatal deaths per 1000 live births in every country by $2035^{12}$. This study was conducted to find out the mortality and morbidity profile in Neonatal Intensive Care Unit (NICU) of a university teaching hospital.

\section{Material and Methods}

This was a retrospective descriptive study where two year data of all neonatal admissions (between $1^{\text {st }}$ January 2015 and $31^{\text {st }}$ December 2016) from NICU of a university teaching hospital were included. After obtaining approval from the Institutional Ethics Committee (IEC), necessary permissions were taken from the hospital authorities. The study hospital was visited on a preinformed date for data collection. Medical records of all neonates in the above mentioned period were reviewed and data extraction from the records was done using a pre-tested proforma.

The proforma included the demographic profile, diagnosis at the time of admission to neonatal ICU, outcomes in terms of mortality and other types of discharges (referral, discharge against medical advice, cure), duration of stay in neonatal ICU and mode of transport used to bring the neonate to hospital. In the mode of transport, the type of ambulance used and self-transportation were documented. The ambulance service also included the State run service named as '108' ambulance. The neonates born in the study hospital were termed as inborn and neonates born in other hospitals or home were termed out born. The collected data were analysed using Statistical Package for the Social Sciences (SPSS) version 11.5. Results were expressed as proportions using appropriate tables. For comparison across the groups, Chi-square test was done and a $p$-value $<0.05$ was considered statistically significant.

\section{Results}

During the study period, a total of 3623 neonates were admitted in the NICU. Out of the total admissions,
95.5\% were inborn neonates and $4.5 \%$ were out born neonates. Admission rates among inborn neonates were $2.9 \%$. Overall, $53.6 \%$ of the total inborn admissions were males and $52.5 \%$ of out born admissions consisted of males. Also, 1596 (44.1\%) neonates weighed 2500 grams or above, $44 \%$ were low birth weight, $9.4 \%$ were very low birth weight and $2.5 \%$ were extremely low birth weight. $52.4 \%$ were term babies, $33.5 \%$ were late preterm and $14.1 \%$ were early preterm. The baseline characteristics of the study population have been depicted in Table 1.

Both among inborn and out born babies, higher proportion were delivered after 37 weeks of gestation (53\% and $38.9 \%$ respectively). Out born neonates had higher mortality rates as compared to inborn neonates (15.4\% v/s 5.5\%). In addition, the DAMA was higher among the out born neonates (10.5\% v/s $3.6 \%)$.

Average duration of stay were 6.5 days for inborn neonates and 8.4 days for out born neonates. In total, $88.3 \%$ of the total admissions were successfully discharged, $1.9 \%$ were referred for further management, $3.9 \%$ were discharged against medical advice and $5.9 \%$ succumbed to complications. Table 2 describes the morbidity details of the neonates. This reflects the various causes which led to these admissions to NICU. Neonatal jaundice $(42.7 \%$ ) was the most common cause for admission in NICU among inborn neonates, followed by sepsis $(26.1 \%)$. Among the out born neonates, Sepsis $(29.7 \%)$ was the most common morbidity.

Overall mortality rate was $5.9 \%(n=215)$ for the NICU admitted neonates; whereas for inborn neonates it was $5.5 \%$ and for out born neonates it was $15.4 \%$. This difference was found to be statistically significant $(p<0.0001)$.

Table 3 depicts the baseline characteristics of the deceased neonates in inborn and out born groups. Of the total deceased, $61.9 \%$ were males and $38.1 \%$ were females. $27.4 \%$ were term neonates and $72.6 \%$ were preterm neonates. Also, 18.6\% neonates weighed 2500 grams or above, $30.7 \%$ were low birth weight, $33 \%$ were very low birth weight and $17.7 \%$ were extremely low birth weight.

Neonatal sepsis $(36.3 \%)$ was the most common cause of mortality followed by Respiratory Distress Syndrome (RDS) seen in $27.4 \%$. Other causes were congenital malformations (18.6\%) followed by hypoxic ischemic encephalopathy (HIE) in 9.8\%, Meconium Aspiration Syndrome (MAS) was seen in $5.1 \%$ and Intra Ventricular Haemorrhage (IVH) in $2.8 \%$ respectively. There was no statistically significant difference observed across the categories for inborn and out born neonates. 
Table 4 describes the causes of death among deceased neonates.

Table 5 describes the association of type of transport used to reach the study hospital with the outcomes among the out born neonates. For the analysis we considered the mortality rate and all other types of discharges from the hospital including cure, referral and DAMA. In total, $02(2.3 \%)$ of the total out born neonates transported through state run ambulance succumbed to the complications. Also, 09 (23.7\%) neonates transported through other ambulances and 14 $(40 \%)$ in self-transportation were among the deceased. This difference was found to be statistically significant $(p<0.0001)$

Table 1: Baseline characteristics and outcomes of admitted neonates in the study hospital $(n=3623)$

\begin{tabular}{|c|c|c|c|c|}
\hline \multirow{2}{*}{\multicolumn{2}{|c|}{ Characteristics }} & \multicolumn{2}{|c|}{ Place of birth } & \multirow[b]{2}{*}{ Total No. (\%) } \\
\hline & & Inborn No. (\%) & Out born No. (\%) & \\
\hline \multirow{2}{*}{ Gender } & Male & $1857(53.6)$ & $85(52.5)$ & 1942 (53.6) \\
\hline & Female & $1604(46.4)$ & $77(47.5)$ & $1681(46.4)$ \\
\hline \multirow{4}{*}{ Birth weight } & $>2500$ grams & $1551(44.8)$ & $45(27.8)$ & $1596(44.1)$ \\
\hline & $1500-2499$ grams & $1508(43.6)$ & $86(53.1)$ & $1594(44.0)$ \\
\hline & $1000-1499$ grams & $0315(09.1)$ & $26(16.0)$ & $0341(09.4)$ \\
\hline & $<1000$ grams & $0087(02.5)$ & $05(03.1)$ & $0092(02.5)$ \\
\hline \multirow{3}{*}{$\begin{array}{l}\text { Period of Gestation at } \\
\text { delivery }\end{array}$} & $>37$ weeks & $1834(53.0)$ & $63(38.9)$ & $1897(52.4)$ \\
\hline & 34-37 weeks & $1162(33.6)$ & $51(31.5)$ & $1213(33.5)$ \\
\hline & $<34$ weeks & 0465 (13.4) & $48(29.6)$ & $0513(14.1)$ \\
\hline \multirow{4}{*}{ Outcome } & Death & $0190(05.5)$ & $25(15.4)$ & $0215(05.9)$ \\
\hline & Discharged & 3083 (89.1) & $115(71.0)$ & 3198 (88.3) \\
\hline & Referral & $0063(01.8)$ & $05(03.1)$ & $0068(01.1)$ \\
\hline & DAMA\# & $0125(03.6)$ & $17(10.5)$ & $0142(03.9)$ \\
\hline Total & & 3461 & 162 & 3623 \\
\hline
\end{tabular}

\# DAMA: Discharge Aagainst Medical Advice

Table 2: Morbidity profile of the neonates admitted during the study period $(n=3623)$

\begin{tabular}{lccc}
\hline Causes & $\begin{array}{c}\text { Inborn }(\mathbf{n = 3 4 6 1 )} \\
\text { No. }(\%)\end{array}$ & $\begin{array}{c}\text { Out born }(\mathbf{n = 1 6 2 )} \\
\text { No. }(\%)\end{array}$ & $\begin{array}{c}\text { Total } \\
\text { No. (\%) }\end{array}$ \\
\hline Jaundice & $1477(42.7)$ & $23(14.2)$ & $1500(41.4)$ \\
\hline Sepsis & $0903(26.1)$ & $48(29.7)$ & $0951(26.2)$ \\
\hline Prematurity \& Low Birth Weight & $0520(15.0)$ & $22(13.6)$ & $0542(15.0)$ \\
\hline Respiratory Distress Syndrome & $0143(04.1)$ & $14(08.6)$ & $0157(04.3)$ \\
\hline Hypoxic Ischemic encephalopathy & $0129(03.7)$ & $11(06.8)$ & $0140(03.9)$ \\
\hline Malformations & $0099(02.9)$ & $09(05.5)$ & $0108(03.0)$ \\
\hline Seizures & $0072(02.1)$ & $23(14.2)$ & $0095(02.6)$ \\
\hline Meconium Aspiration Syndrome & $0048(01.4)$ & $12(07.4)$ & $0060(01.7)$ \\
\hline Hypoglycemia & $0047(01.3)$ & 0 & $0047(01.3)$ \\
\hline Hypothermia & $0023(00.7)$ & 0 & $0023(00.6)$ \\
\hline
\end{tabular}

Table 3: Baseline characteristics of deceased neonates during the study period $(n=215)$

\begin{tabular}{|c|c|c|c|c|c|}
\hline \multicolumn{2}{|c|}{ Characteristics } & $\begin{array}{l}\text { Inborn } \\
\text { No. (\%) }\end{array}$ & $\begin{array}{c}\text { Out born } \\
\text { No. (\%) }\end{array}$ & $\begin{array}{c}\text { Total } \\
\text { No. }(\%)\end{array}$ & $p$-value \\
\hline \multirow{2}{*}{ Gender } & Male & $117(61.6)$ & $16(64.0)$ & $133(61.9)$ & \multirow{2}{*}{0.815} \\
\hline & Female & $073(38.4)$ & $09(36.0)$ & $082(38.1)$ & \\
\hline \multirow{3}{*}{ Birth weight } & $>2500 \mathrm{~g}$ & $036(19.0)$ & $04(16.0)$ & $040(18.6)$ & \multirow{3}{*}{0.910} \\
\hline & $1000-2499 g$ & $121(63.7)$ & $16(64.0)$ & $137(63.7)$ & \\
\hline & $<1000 \mathrm{~g}$ & $033(17.3)$ & $05(20.0)$ & $038(17.7)$ & \\
\hline \multirow{2}{*}{ Gestation } & Term & $052(27.4)$ & $07(28.0)$ & $059(27.4)$ & \multirow{2}{*}{0.947} \\
\hline & Preterm & $138(72.6)$ & $18(72.0)$ & $156(72.6)$ & \\
\hline Total & & $190(100)$ & $25(100)$ & $215(100)$ & \\
\hline
\end{tabular}


Table 4: Causes of death among the neonates admitted during the study period $(n=215)$

\begin{tabular}{ccccc}
\hline Causes & $\begin{array}{c}\text { Inborn } \\
\text { No. (\%) }\end{array}$ & $\begin{array}{c}\text { Out born } \\
\text { No. (\%) }\end{array}$ & $\begin{array}{c}\text { Total } \\
\text { No. (\%) }\end{array}$ & p-value (X2 test) \\
\hline Sepsis & $68(35.8)$ & $10(40.0)$ & $78(36.3)$ & 0.681 \\
\hline RDS & $52(27.4)$ & $07(28.0)$ & $59(27.4)$ & 0.947 \\
\hline Malformations & $36(19.0)$ & $04(16.0)$ & $40(18.6)$ & 1.000 \\
\hline HIE & $19(10.0)$ & $02(08.0)$ & $21(09.8)$ & 1.000 \\
\hline MAS & $09(04.7)$ & $02(08.0)$ & $11(05.1)$ & 0.621 \\
\hline IVH & $06(03.1)$ & 00 & $06(02.8)$ & 1.000 \\
\hline Total & $\mathbf{1 9 0 ( 1 0 0 )}$ & $\mathbf{2 5 ( 1 0 0 )}$ & $\mathbf{2 1 5 ( 1 0 0 )}$ & \\
\hline
\end{tabular}

Table 5: Association between mode of transport and outcomes among the out born neonates $(n=162)$

\begin{tabular}{lcccc}
\hline \multirow{2}{*}{$\begin{array}{l}\text { Transport to study } \\
\text { hospital }\end{array}$} & $\begin{array}{c}\text { Mortality } \\
\text { No }(\%)\end{array}$ & $\begin{array}{c}\text { Others } \\
\text { No }(\%)\end{array}$ & Total & X2 for trend; \\
p-value
\end{tabular}

${ }^{*} p$-value significant at 0.05 level

\section{Discussion}

This study was conducted to know the morbidity pattern, outcome and various causes of mortality in neonates admitted in NICU of a university teaching hospital. In this study, of the total of 3623 admissions, $95.5 \%$ were inborn when compared to $4.5 \%$ out born neonates. There was male predominance with respect to NICU admissions. Similar finding with respect to the gender distribution was reported by several studies $^{1,6,13,14,15,16}$. Overall, $45.9 \%$ of admissions were of low birth weight and $47.6 \%$ were preterm neonates. This was in line with the findings from the study conducted by Modi et al ${ }^{1}$. Neonatal jaundice was the single most cause of admission in NICU and this was similar to the findings from study done by Harsha et $\mathrm{al}^{13}$. Sepsis, respiratory distress syndrome, meconium aspiration syndrome and birth asphyxia were the other leading causes of admission. Duration of stay in NICU was slightly higher for out born when compared to inborn babies. This may be due to the fact that the inborn neonates arrive at the NICU earlier and faster as compared to out born neonates. Due to this the out born neonates would need higher and longer duration of care at the hospital. The preterm birth rate was $14.7 \%$ of which $8.4 \%$ developed RDS, $0.4 \%$ developed IVH and $0.2 \%$ developed Retinopathy of Prematurity (ROP). This is in contrast to Kong $X$ et al study, where higher incidence of RDS, IVH and ROP were observed in preterm babies ${ }^{17}$.

Successful discharge was higher (88.3\%) and mortality rate was lower $(5.9 \%)$ in this study compared to the study by Gauchan et al ${ }^{18}$. Neonatal mortality was higher in low birth weight and preterm babies, similar to several other studies ${ }^{6,16,17}$. Of the total out born preterm babies, mortality rate was $18.2 \%$ which was higher than the mortality rate observed in inborn preterm babies (8.5\%). Higher neonatal mortality in out born preterm babies addresses the need for intrauterine transport to higher centres which may reduce the mortality in out born preterm babies.

Worldwide, prematurity, sepsis and birth asphyxia are the leading causes of death among neonates ${ }^{19}$. In our study, neonatal sepsis (36.3\%) was the major cause of mortality. Sepsis as a cause of neonatal mortality was higher in our NICU compared to the global rate of $26 \%$. This implies the need for sepsis control measures which is a preventable cause of death. Respiratory distress syndrome and congenital malformations were ranked second and third. Also level of congenital malformations as a cause of death in our study was similar to that of a study by Wang et $\mathrm{al}^{20}$. The study hospital is a tertiary care University teaching hospital which may explain the higher rate of neonates with congenital malformations.

The mortality rate was higher among out born neonates when compared to inborn neonates. This finding was similar study by Panda et $\mathrm{al}^{21}$. Among out born neonates, those who were brought to the hospital by ambulances had lesser death rates when compared to those brought by any means of self-transport. Among the ambulance services, private ambulance transportation carried a higher risk when compared to the 
State run ambulance. This could reflect the availability of emergency care within the ambulance as compared to the other vehicles, which can eventually reduce the complications and thereby death rates. It could also be that availability and accessibility of ambulance services in certain areas, could influence the transport pattern of people during emergencies. Studies comparing the association between mode of transport and outcomes are limited. This can bring about the need for wellequipped transport mechanism to be made available for neonates during emergencies.

In India, which has a population close to 1.3 billion, there is a need to have a database both at national and regional levels, with analyses of neonatal, infant and child (under the age of 5 years) deaths. This could help in assessing and targeting the health resources towards child survival measures across all over with special emphasis on areas with high child mortality ${ }^{22}$.

\section{References}

1. Modi R, Modi B, Patl JK, Punitha KM. Study of the Morbidity and the Mortality Pattern in the Nonatal Intensive Care Unit at a Tertiary Care teaching Hospital in Gandhinagar District, Gujarat, India. J Res Med Den Sci 2015;3:208-12. DOI: 10.5455/jrmds.20153311

2. WHO | Global Health Observatory $(\mathrm{GHO})$ data. Available at: http://www.who.int/gho/en/

3. Manhas S. A Critical Analysis of Childhood Morbidity and Mortality Pattern in India: Trends and Disparities. Asian J Sci Tecnol 2016;7:2912-918.

4. Tran HT, Doyle LW, Lee KJ, Graham SM. A systematic review of the burden of neonatal mortality and morbidity in the ASEAN Region. WHO South East Asia J Public Health. 2012;1:239-48. DOI: 10.4103/22243151.207020

5. Roy KK, Baruah J, Kumar S, Malhotra N, Deorari AK, Sharma JB. Maternal Antenatal Profile and Immediate Neonatal Outcome in VLBW and ELBW Babies. Indian J Pediatr 2006;73:31-5. DOI: 10.1007/BF02898441

6. Kumar MK, Thakur SN, Singh BB. Study of the Morbidity and the Mortality Patterns in the Neonatal Intensive Care Unit at a Tertiary Care Teaching Hospital in Rohtas District, Bihar, India. J Clin Diagn Res 2012;6:282-5. DOI: JCDR/3687:1994

7. Sankar MJ, Neogi SB, Sharma J, Chauhan M, Srivastava R, Prabhakar PK, et al. State of newborn health in India. J Perinatol 2016;36:S3-8. DOI: 10.1038/jp.2016.183

8. Sangamam R. Perinatal mortality and morbidity among low birth weight babies. Int J Community Med Public Health 2015;2:51-58. DOI: 10.5455/2394-6040. ijcmph20150211
The limitations of this study include, the data was not representative of the community as it was hospital based study, and still-born rates were not taken in to consideration. Sepsis prevention measures, intrauterine transport, early referral of neonates to centres with better facilities and transport through well-equipped ambulances may help to reduce neonatal mortality as observed from analysis of neonatal mortality in this study, however we have not done interventional study to prove the same.

\section{Conclusion}

LBW and prematurity formed a major proportion of admitted neonates in the study hospital. Neonatal sepsis, respiratory distress syndrome and congenital malformations were the major causes of mortality. Understanding causes of neonatal mortality may help to implement interventions to promote new-born survival.

9. Lawn JE, Cousens S, Zupan J, Lancet Neonatal Survival Steering Team. 4 million neonatal deaths: When? Where? Why?. Lancet 2005;365:891-900. DOI: 10.1016/S0140-6736(05)71048-5

10. Nagarajarao V, Ahmed M, Ravi A, Pattabhirama GH, Balasundaram K. A study of early neonatal morbidity profile in a district teaching hospital, Mysore, India. Int J Med Public Health 2014;4:396-9. DOI: 10.4103/22308598.144079

11. Upadhyay RP, Chinnakali P, Odukoya O, Yadav K, Sinha S, Rizwan $S$ et al. High neonatal mortality rates in rural India: what options to explore? ISRN Pediatr 2012;2012:968921. DOI: 10.5402/2012/968921

12. Bhutta ZA, Das JK, Bahl R, Lawn JE, Salam RA, Paul VK et al. Can available interventions end preventable deaths in mothers, newborn babies, and stillbirths, and at what cost? Lancet 2014;384:347-70. DOI: 10.1016/ S0140-6736(14)60792-3

13. Harsha PJ, lyer CR, Rathod AD, Nagendra K, Chandan CK, Gornale VK. A Prospective observational study of short term morbidity pattern in preterm newborns delivered in a tertiary care hospital. J Evidence based Med Healthcare 2015;2:5432-37. DOI: 10.18410/ jebmh/2015/755

14. Malik S, Gohiya P, Khan IA. Morbidity profile and mortality of neonates admitted in Neonatal Intensive Care Unit of a Central India Teaching Institute: A prospective observational study. J Clin Neonatol 2016;5:168-73. DOI: 10.4103/2249-4847.191251

15. Baruah MN, Panyang PP. Morbidity and Mortality Profile of Newborns Admitted to the Special Care Newborn Unit ( SCNU ) of A Teaching Hospital of Upper Assam,India - A Three Year Study. J Med Sci Clin Res 2016;4:11689-95. DOI: 10.18535/jmscr 
16. Abdellatif $M$, Ahmed $M$, Bataclan MF, Khan $A A, A$ Battashi A, Al Maniri A. The Patterns and Causes of Neonatal Mortality at a Tertiary Hospital in Oman. Oman Med J 2013;28:422-6. DOI: 10.5001/omj.2013.119

17. Kong X, Xu F, Wu R, Wu H, Ju R, Zhao X et al. Neonatal mortality and morbidity among infants between 24 to 31 complete weeks: a multicenter survey in China from 2013 to 2014. BMC Pediatr 2016;16:174. DOI: 10.1186/s12887-016-0716-5

18. Gauchan E, DP BS, Rao KS. Clinical profile and outcome of babies admitted to Neonatal Intensive Care Unit (NICU). J Inst Med 2011;33(2):1-8.

19. WHO. Newborn death and illness. Available at: http:// www.who.int/pmnch/media/press_materials/fs/fs_ newborndealth_illness/en/
20. Wang $\mathrm{CH}$, Du LZ, Ma XL, Shi LP, Tong XM, Liu H et al. Analysis of In-hospital Neonatal Death in the Tertiary Neonatal Intensive Care Unit in China: A Multicenter Retrospective Study. Chinese Med J 2016;129:2652. DOI: $10.4103 / 0366-6999.193458$

21. Panda S. Mortality \& morbidity profile in vlbw \& elbw neonates admitted to $\mathrm{NICU}$ in $\mathrm{HMCH}$. Yuva J Med Sci 2016;1:51-5.

22. Kumar GA, Dandona $R$, Chaman $P$, Singh $P$, Dandona L. A population-based study of neonatal mortality and maternal care utilization in the Indian state of Bihar. BMC Pregnancy Childbirth 2014,14:357. DOI : 10.1186/1471-2393-14-357. 